Limits to arbitrage: the case of single stock futures and spot prices

Nidhi Aggarwal

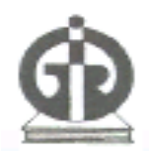

Indira Gandhi Institute of Development Research, Mumbai May 2015

http://www.igidr.ac.in/pdf/publication/WP-2015-10.pdf 


\title{
Limits to arbitrage: the case of single stock futures and spot prices
}

\author{
Nidhi Aggarwal \\ Indira Gandhi Institute of Development Research (IGIDR) \\ General Arun Kumar Vaidya Marg \\ Goregaon (E), Mumbai- 400065, INDIA
}

Email(corresponding author): nidhi@igidr.ac.in

\begin{abstract}
Market frictions limit arbitrage, but these frictions affect different stocks differently. Using intraday data on a liquid single stock futures and spot market, we examine the arbitrage efficiency of these two markets. We find evidence of significant cross- sectional variation in the size and asymmetricity of no-arbitrage bands. To the extent that market frictions affect all stocks similarly, commonality in the size of the bands is expected. 17\% of variation in the size of the bands is explained by the first principal component. Changes in funding liquidity is a key factor that determines variation in the common component.
\end{abstract}

Keywords: Limits to arbitrage, mispricing, no-arbitrage bands, short-selling constraints, transactions costs, funding constraints

JEL Code: G13, G14

\section{Acknowledgements:}

Email address: nidhi@igidr.ac.in. I am grateful to Susan Thomas and Ajay Shah for useful comments and suggestions. I would like to thank the National Stock Exchange, India for the data used in this paper. All errors remain my own. 


\title{
Limits to arbitrage: The case of single stock futures and spot prices
}

\author{
Nidhi Aggarwal*
}

March 2015

\begin{abstract}
Market frictions limit arbitrage, but these frictions affect different stocks differently. Using intraday data on a liquid single stock futures and spot market, we examine the arbitrage efficiency of these two markets. We find evidence of significant crosssectional variation in the size and asymmetricity of no-arbitrage bands. To the extent that market frictions affect all stocks similarly, commonality in the size of the bands is expected. $17 \%$ of variation in the size of the bands is explained by the first principal component. Changes in funding liquidity is a key factor that determines variation in the common component.
\end{abstract}

Keywords: Limits to arbitrage, Mispricing, No-arbitrage bands, Short-selling constraints, Transactions costs, Funding constraints

JEL Classification: G13, G14

*The author is with the Finance Research Group, IGIDR Email address: nidhi@igidr.ac.in. I am grateful to Susan Thomas and Ajay Shah for useful comments and suggestions. I would like to thank the National Stock Exchange, India for the data used in this paper. All errors remain my own. 


\section{Introduction}

"It is good for a scientific enterprise, as well as for a society, to have well-established laws. Physics has excellent laws, such as the law of gravity. What does economics have? The first law of economics is clearly the law of supply and demand, and a fine law it is. We would nominate as the second law "the law of one price," hereafter simply the Law."

- Lamont and Thaler (2003)

The law of one price is the basic building block of finance theory. It states that identical goods should trade at identical prices. If not, arbitrage opportunities emerge and bring back the prices to the same level. Theoretically, arbitrage requires no capital, involves no transactions costs and is riskfree. However, in reality, limits to arbitrage in the form of market frictions such as explicit (taxes, turnover charges) and implicit costs (liquidity costs), funding constraints, regulatory restrictions like short selling constraints exist (Shleifer and Vishny, 1997; Gromb and Vayanos, 2002). These factors collectively make arbitrage difficult and result in persistent deviations in the prices of similar goods. This results in formation of noarbitrage bands around the prices of the securities within which arbitrage is not profitable. Arbitrageurs enter the market only when the deviations are large enough to compensate them for the costs, that is, when the deviations are outside the no-arbitrage bands.

Substantial market microstructure literature has focused on identifying these market frictions and its impact on the arbitrage efficiency in the capital markets. The pair of securities examined include index futures and spot,1] stock options and spot (Ofek et al., 2004; Cremers and Weinbaum, 2010), and very recently, internationally cross-listed securities such as American depository receipts (ADRs), and their home-market security prices (Gagnon and Karolyi, 2010). Though perfect substitutes by themselves, these set of pairs suffer from various issues. For example, index futures and spot arbitrage suffers from stale price issues, difficulties in trading the entire basket of securities with appropriate weights at the same time (Miller et al., 1994). Similarly, studies on cross-listed pairs face challenges related to asynchronous trading due to non-overlapping trading hours, complexities related to determining the full extent of transactions costs, regulatory restrictions on foreign ownership Gagnon and Karolyi, 2010).

In contrast, single stock futures (SSF) and spot offer a clean setting to analyse arbitrage efficiency and eliminate issues related to index trading, estimation risk in options and crosslisted pairs of securities. Yet, not much empirical evidence exists regarding the arbitrage efficiency of these markets. A probable reason for this could be the illiquidity of the SSF

\footnotetext{
${ }^{1}$ See (Cornell and French, 1983; Modest and Sundaresan, 1983 Figlewski, 1984, Mackinlay and Ramaswamy, 1988, Yadav and Pope, 1990; Klemkosky and Lee, 1991; Chung, 1991; Gay and Jung, 1999 Yadav et al. , 1994, Dwyer et al. , 1996; Martens et al., 1998; Forbes et al., 1999; Ackert and Tian, 2001; Tse, 2001; McMillan and Speight, 2006: Kim et al. | 2010).
} 
markets world over. We fill this missing gap by analysing the arbitrage efficiency in a market with high liquidity on both the spot as well as the SSF market. Using intraday data over the period between March 2013 to August 2013 on 141 pairs of single stock futures and spot prices at the National Stock Exchange, India, we examine how market frictions shape-up the no-arbitrage bands on the spot and SSF prices, and how these bands vary with varying liquidity across stocks. Higher liquidity facilitates arbitrage by reducing costs (Roll et al. 2007). Thus, the width of no-arbitrage bands for stocks with higher liquidity is expected to be smaller than that of the stocks with lower liquidity.

In addition, the presence of short selling constraints on the spot market adversely affects arbitrage on the negative side. Studies including Yadav et al. (1994), Dwyer et al. (1996), Brooks and Garrett (2002), Fung and Draper (1999), McMillan and Speight (2006) analyse index spot and futures prices and find that short selling constraints widen the no-arbitrage bands on the negative side due to higher costs involved in entering the spot position. Using data on options prices, Ofek et al. (2004) find that violations of put-call parity are asymmetric in the direction of short sales constraints, and their magnitudes are strongly related to the cost and difficulty of short selling. The recent research focusing on the 2008-09 short sales ban in the US market also finds an adverse impact of short selling on the equity markets. McMillan and Philip (2012) perform a cross-country analysis of the impact of short sales ban during 2008-09 on the index spot-futures efficiency. They find that the ban caused the basis to be lower than in the normal periods, with the speed of adjustment coming down. For single stocks, we expect short selling constraints to affect different stocks differently, depending on the ease with which the stocks can be borrowed $!^{2}$ Thus, we examine if the no-arbitrage bands exhibit an asymmetric behavior, and if there is cross-sectional variation in the asymmetricity. Since it is relatively easier to borrow liquid stocks than the illiquid ones, we expect larger asymmetricity in the bands for the illiquid stocks.

Using non-linear threshold autoregressive models, we find evidence of no-arbitrage bands around spot and SSF prices. When mispricing is positive, we find that the average upper threshold across all stocks is 3 basis points. This implies that when the SSF prices are overpriced than the spot prices to the extent of 3 basis points, arbitrageurs are unlikely to enter the market. On the negative side, that is, when spot is overpriced and SSF is underpriced, the threshold limit is much higher, at 15 basis points. This asymmetricity in the upper and lower threshold can be explained by the short selling constraints that exist on the spot market. We also find significant cross-sectional variation in the size of the bands across stocks. The size of the no-arbitrage bands and asymmetricity increases with decreasing liquidity of the stocks.

We next examine the commonality in the no-arbitrage bands across stocks. The evidence so far with regard to commonality relates to returns, trading activity, order flow, liquidity $\left.\right|^{3}$ We

\footnotetext{
${ }^{2}$ Factors determining the ease with which stocks can be borrowed include the percentage of stock available in the market as floating stock, stock liquidity (Nagel, 2005).

${ }^{3}$ See Fama and French (1995), Chordia et al. (2000), Huberman and Halka (2001), Lee et al. (2012), Karolyi et al. $[2012)$.
} 
hypothesise that frictions related to arbitrage activity is composed of two major components: frictions arising out of market factors such as taxes, market liquidity, market volatility, funding liquidity, and idiosyncratic factors related to the stock specific liquidity, returns volatility. To the extent that market frictions affect all stocks similarly, we expect a common factor in the no-arbitrage bands that can be attributed to the systematic component of trading frictions.

We further investigate the factors that drive the commonality, or the variation in the systematic factor. Changes in explicit trading costs, funding costs, microstructual variables such as liquidity, liquidity risk, stock volatility are the factors that are likely to drive the commonality. We examine the determinants of commonality using regression analysis.

Using principal component analysis, we find evidence of significant commonality in the size of the no-arbitrage bands across stocks. We find that about $34 \%$ of the variation in the size of no-arbitrage bands across stocks can be explained by the first three principal components, with the first factor explaining about $17 \%$ variation. We refer to the first factor as the systematic component. This finding links with the commonality literature which has so far focused on commonality in returns, liquidity, order flow, trading activity, and very recently, market efficiency (Rosch et al., 2014).

The period of the analysis covers an interesting phase of tightening of funding liquidity in mid-July 2013. Due to an intense pressure on the exchange rate, the central bank of India, intervened in the money markets by raising the interest rates. This sudden and significant increment raised the funding costs for the traders and affected the arbitrage efficiency adversely. We find evidence that the day when the interest rates were raised, the systematic factor of the no-arbitrage bands went up significantly, indicating the worsening of arbitrage efficiency in the equity markets. Our regression results provide further evidence of how funding constraints are the most important factor in determining the arbitrage efficiency even for SSF and spot prices.

The regression results indicate that explicit factors such as taxes, microstructual factors like market liquidity and volatility play a significant role in explaining the variation in commonality of the size of no-arbitrage bands. We find that the factor that affects the commonality most significantly is funding constraints. More than $18 \%$ of variation in the systematic component of the no-arbitrage bands can be explained by funding constraints. This evidence is consistent with the recent literature that asserts that funding liquidity is a key factor in determining market liquidity and thus market efficiency (Brunnermeier and Pedersen, 2009; Gagnon and Karolyi, 2010; Rosch et al., 2014).

The rest of the paper is organised as follows: Section 2 describes the market structure at NSE, Section 3 explains data and variables used in the analysis. Section 4 documents evidence on the presence of no-arbitrage bands and cross-sectional variation in bandsize and asymmetricity. Section 5 discusses the results of principal component analysis providing evidence of commonality in the size of no-arbitrage bands. Section 6 examines the factors that determine the variation in commonality. Section 7 concludes. 


\section{Market structure}

This paper focuses on the equity spot and the futures market of the National Stock Exchange, India (NSE). In contrast to the global markets, NSE has a unique setting where both, the spot and the futures market trade at the same platform. Thus, there are no issues related to time asynchronicity. Unlike the single stock futures market around the world, these contracts are actively traded on the NSE platform, making it one of the top five exchanges in the world that trades single stock futures $4^{4}$ Some of the unique market features at NSE are described below:

Trading Trading on both the spot and the futures market is done through a fully automated electronic limit order book time with orders executed on a price-time priority basis. In addition to NSE, Bombay Stock Exchange is another major stock exchange that offers equity spot and futures trading. However, majority of volumes on both the markets are concentrated on the NSE.

The current trading hours are between 9:00 am to 3:30 pm. Trading begins through a call auction market which starts at 9:00 am and continues until 9:15 am. From 9:15 am onwards, the markets enter the continuous trading system.

Out of about 1500 securities that are listed and traded on the NSE equity spot segment, only about 141 securities are traded on the derivatives market during the period of study. The selection of the securities to be traded on derivatives segment is made on the basis of liquidity of the contract. The futures contracts are one-month, two-month and three-month contracts. As in other global markets, most of the trading is concentrated in the near-month contracts. The tick size on both the spot and the SSF market is 5 paise (5\%).

Short selling constraints and the SLB scheme Short selling is not permitted on the equity spot market. To enable traders to lend and borrow securities, Security Lending and Borrowing Scheme (SLBS) was introduced by the NSE in April 2008 $5^{5}$ Just as the spot and futures market, this platform enables lending and borrowing of stocks through an anonymous automated screen based mechanism with order matching done on price time priority. However, the activity on the SLB scheme has remained relatively low ${ }^{6}$

Trading costs Trading involves explicit costs that the traders are charged upfront, such as brokerage, transaction charges, securities transaction tax (STT), and implicit costs that the trader faces as liquidity costs of trading.

Table 1 gives a summary of the explicit transaction costs that a trader faces while trading on equity markets in India. In addition to the costs mentioned in the table, the trader is charged a brokerage fee which varies as per the turnover. Service tax of $12.36 \%$ is charged on the brokerage and transaction charges.

Clearing and Settlement Settlement on the spot market is conducted on a $T+2$ basis and on a $T+1$ basis for the SSF market. The SSF are cash settled instead of physically settled.

\footnotetext{
${ }^{4}$ http://www.world-exchanges.org

${ }^{5}$ See wWw.nseindia.com/products/content/equities/slbs/slbs_trades_archives.htm

${ }^{6}$ See Suvanam and Jalan (2012), Grover (2014).
} 
Table 1 Summary of explicit costs of trading

Summary of explicit transaction charges a trader faces on trading in the Indian equity markets in 2013. All charges are charged as a percentage of total turnover.

\begin{tabular}{l|ccc}
\hline Charges & Equity Delivery & Equity Intra-day & Futures \\
\hline $\begin{array}{l}\text { Securities } \\
\text { Transactions Tax }\end{array}$ & $0.100 \%$ & $\begin{array}{c}0.025 \% \text { only on } \\
\text { sell-side trade }\end{array}$ & $\begin{array}{c}0.017 \% \text { (until May 31, 2013) } \\
0.010 \% \text { (w.e.f Jun 1, 2013) } \\
\text { only on sell-side trade }\end{array}$ \\
\hline $\begin{array}{l}\text { NSE Transactions } \\
\text { Charges }\end{array}$ & $0.0035 \%$ & $0.0035 \%$ & $0.002 \%$ \\
\hline $\begin{array}{l}\text { SEBI Turnover } \\
\text { Charges }\end{array}$ & NIL & NIL & $0.0002 \%$ \\
\hline Stamp Duty & $0.01 \%$ & $0.002 \%$ & $0.002 \%$
\end{tabular}

Unlike most other global markets, traders pay daily margins on both the spot as well as the SSF positions.

\section{$3 \quad$ Data and market variables}

\subsection{Data details}

The analysis uses intraday limit order book data from March 1, 2013 to August 31, 2013 (120 trading days) for all the 141 stocks traded on the derivatives segment of the NSE. The data are obtained from the National Stock Exchange and comprise of price and quantity information up to twenty best bid and ask quotes. We use near month SSF data, and rollover to the next contract two days prior expiration. One-month Mumbai Inter-Bank Offer Rate (MIBOR) is used as a proxy to capture the interest rate borne by the traders to borrow from the market. MIBOR is a benchmark reference rate for the deals in the money market. It is disseminated jointly by the Fixed Income Money Market and Derivatives Association of India (FIMMDA) and NSE. In order to derive it, market participants are polled regarding their expectations of the interest rates, and an average is taken after segregating the noise.

The period of study covers an interesting phase of tightness in funding liquidity. In mid-2013, the Indian Rupee experienced significant volatility as a result of expectations of a tapering of quantitative easing by the Federal Reserve Bank, US. The Indian currency depreciated by about 17\% in the period between May 15, 2013 to August 20, 2013. As a result, the central bank of India undertook several measures to counter the significant currency depreciation 7 On July 15, 2013, the central bank indirectly intervened in the money markets by increasing

\footnotetext{
${ }^{7}$ See Shah 2013 .
} 
the interest rates and constraining the funds available under the liquidity adjustment facility 8 These actions had a sharp impact on the short term interest rates, with MIBOR increasing from $7.88 \%$ on July 15, 2013 to $9.23 \%$ on July 16, 2013. This tightening in the interest rates provides an interesting event to analyse how changes in funding liquidity impacts traders and thus the arbitrage efficiency of the markets.

In addition, the period also saw a microstructual change, in terms of a relaxation in the securities transactions tax (STT) paid by the traders on the futures market. Beginning July 1, 2013, the STT was reduced from $1.7 \mathrm{bp} \mathrm{q}^{9}$ to $1 \mathrm{bps}$.

Table 2 provides descriptive statistics of the sample used in the analysis. Average statistics for the entire sample as well sub-samples based on liquidity costs are indicated. We use the sum of the roundtrip bid-ask spreads on the spot and the SSF segment as a proxy to capture liquidity costs for arbitrage.

\section{Table 2 Sample characteristics}

The table provides average daily descriptive statistics of the sample of stocks analysed in the study. The statistics are presented for the full sample as well as sub-samples based on liquidity quartiles. The daily values of each variable is first averaged across all days for a stock, then an average across all stocks in a set is taken. Number of trades are reported only for the spot market. Q1 indicates the set of most liquid stocks, while Q4 indicates the set of least liquid stocks.

\begin{tabular}{|c|c|c|c|c|}
\hline \multirow{2}{*}{$\begin{array}{l}\text { Liquidity } \\
\text { quartiles }\end{array}$} & Market Cap & Price & \# of trades & Traded value \\
\hline & (Rs.) & (Rs.) & & $\begin{array}{l}\text { Spot SSF } \\
\text { (Rs. Million) }\end{array}$ \\
\hline All & 330,121 & 579.74 & 27,116 & $\begin{array}{ll}573 & 1,022\end{array}$ \\
\hline Q1 (Most) & 837,658 & 828.13 & 55,879 & 1,491 \\
\hline Q2 & 295,613 & 614.79 & 25,793 & 422 \\
\hline Q3 & 81,306 & 226.89 & 16,436 & 208 \\
\hline Q4 (Least) & 76,066 & 625.57 & 8,853 & 196 \\
\hline
\end{tabular}

We next discuss the measurement of variables used in the analysis.

\subsection{Market variables}

Basis $\left(z_{t}\right)$ : We measure basis of a stock at time $t$ as the deviation of the observed futures price of that stock from the theoretical futures price as derived from the simple cost of carry model. It is computed as:

$$
z_{i, t}=\frac{F_{i, t}-S_{i, t} \times \exp \left(r_{t}-d_{t}\right)(T-t)}{S_{i, t}}
$$

\footnotetext{
${ }^{8}$ See: RBI Press Release, July 15, 2013 http://www.rbi.org.in/scripts/BS_PressReleaseDisplay. aspx?prid=29086

'. $\mathrm{bps}$ ' stands for basis points. $100 \mathrm{bps}=1 \%$.
} 
where $F_{i, t}$ is the midquote ${ }^{10}$ price of futures for stock $i$ at time $t, S_{i, t}$ is the spot midquote price for stock $i$ at time $t, r_{t}$ is the risk-free rate for lending and borrowing over the remaining life of the contract $(T-t)$, and $d_{t}$ is the dividend yield over the contract lifetime. We use MIBOR as the risk-free rate 11

Basis risk $\left(\sigma_{z}\right)$ : Basis risk of a stock captures the variability in the basis. Higher basis risk induces greater risk in the arbitrage position. We capture basis risk as the standard deviation of the basis of a stock in a five minutes interval.

Liquidity costs (LiqCosts) : Beyond the explicit costs, an arbitrageur faces liquidity costs in the form of price impact. In a cash-and-carry arbitrage (when $z_{t}$ is positive), the arbitrageur incurs liquidity costs in buying spot and selling futures, and then reversing both the positions whether before expiry or at expiry. Similarly for the reverse-cash-and-carry arbitrage (when $z_{t}$ is negative). We use the sum of quoted bid-ask spread on the spot and the SSF market as a proxy to capture the round-trip liquidity costs incurred in undertaking an arbitrage position.

Liquidity risk $\left(\sigma_{l i q}\right)$ : Just as basis risk, to capture variation in liquidity, we compute the standard deviation of quoted spread within every five minutes interval. This is done separately for the spot and the SSF market.

Stock volatility $\left(\sigma_{r}\right)$ : We capture intraday volatility of the stock as the standard deviation of returns within a five minutes interval for the spot as well as the SSF market.

Barring the basis, higher values of each measure described above make arbitrage risky and costly, which deter the arbitrageur from undertaking an arbitrage position. This results in the basis (or the mispricing error) to be persistent for longer periods of time. Each measure is computed at a 1-second frequency for each stock each day. The median value within the day is used as the value for the day. 12

Table 3 reports the summary statistics of market variables described above for the sample as well as sub-samples based on liquidity costs. The table shows that for all stocks in the sample, as well as across all liquidity quartiles, the median value of basis is negative. The negative value is indicative of the effect of the short sales constraints that are prevalent on the spot market. A positive basis can be corrected by selling SSF and buying spot. However, a negative basis requires selling of spot and buying futures, which requires an active securities lending market. The absence of an active securities lending and borrowing market in India makes it difficult for arbitrageurs to borrow shares on the spot, and correct the mispricing (Suvanam and Jalan, 2012; Grover, 2014).

The table also indicates the variability in the basis, captured by basis risk. Higher is the basis risk, higher is the risk associated in undertaking an arbitrage position. As we move

\footnotetext{
${ }^{10}$ Midquote price is the average of the bid and the ask price.

${ }^{11}$ We do not account for dividend yield in the computation of basis. Miller et al. (1994) argue that since stocks go ex-dividend overnight, if overnight price changes are excluded, the effect of dividend is completely removed. In the analysis, we use intraday values of the basis at one second frequency.

${ }^{12}$ All risk measures $\left(\sigma_{z}, \sigma_{l i q}, \sigma_{r}\right)$ are annualised by multiplying the daily value by $\sqrt{252}$.
} 
Table 3 Sample summary statistics of market variables

The table reports summary statistics of market variables for full sample as well as sub-sample of stocks based on liquidity costs quartiles. For each stock each day, we compute these values at one second level, and then take the median value for the day. We average these values across all days for a stock, and then average across all stocks. Liquidity costs (LiqCosts) are the roundtrip costs incurred on the SSF and spot market proxied by quoted spread. Basis $\left(z_{t}\right)$ and liquidity costs (LiqCosts) are indicated as \% of midquote price. All risk measures captured by $\sigma_{r}, \sigma_{z}, \sigma_{l i q}$ are annualised values.

\begin{tabular}{lcccccccc} 
& & & & & \multicolumn{4}{c}{ All values in \% } \\
\hline $\begin{array}{l}\text { Liquidity } \\
\text { quartiles }\end{array}$ & $\begin{array}{c}\text { \# of } \\
\text { stocks }\end{array}$ & $z_{t}$ & $\sigma_{z}$ & LiqCosts & \multicolumn{2}{c}{$\sigma_{\text {liq }}$} & \multicolumn{2}{c}{$\sigma_{r}$} \\
\cline { 6 - 9 } All & 141 & -0.06 & 1.43 & 0.18 & 0.48 & 0.32 & 34.6 & 44.9 \\
& & & & & & & & \\
Q1 (Most) & 37 & -0.07 & 0.95 & 0.09 & 0.32 & 0.16 & 29.3 & 36.4 \\
Q2 & 34 & -0.07 & 1.27 & 0.16 & 0.48 & 0.32 & 33.7 & 40.7 \\
Q3 & 34 & -0.04 & 1.59 & 0.24 & 0.64 & 0.48 & 38.8 & 51.1 \\
Q4 (Least) & 36 & -0.03 & 1.90 & 0.33 & 1.11 & 0.69 & 39.0 & 53.1
\end{tabular}

away from the most liquid to the less liquid securities, basis risk increases which raises the risk in the arbitrage position and thus, reduces the incentive for arbitrageurs to correct the mispricing.

The next column in the table indicates the roundtrip liquidity costs incurred by the arbitrageur to undertake the two positions. We observe a significant variation in the liquidity costs across sub samples as proxied by the roundtrip bid-ask spread. For the most liquid stocks, liquidity costs are at an average $9 \mathrm{bps}$, while that for the least liquid is $33 \mathrm{bps}$. Also, it turns out that liquidity risk is higher on the spot market than on the SSF market. The last two column indicate the returns volatility on the spot and the SSF market. As expected, returns volatility is higher for illiquid stocks than the liquid stocks. We also observe significant difference in the variance of returns on the spot and the SSF market for stocks in the least liquid quartile.

\section{Market frictions and the no-arbitrage bands}

In perfect markets with no market frictions, the value of $z_{t}$ is expected to be zero. However, in reality, market frictions exist, and cause $z_{t}$ to be a non-zero value. These frictions include: transactions costs, short selling constraints and funding constraints.

Transactions costs include explicit and implicit costs that are incurred when positions are opened or closed (Modest and Sundaresan, 1983; Yadav and Pope, 1990; Brenner et al., 1990). Explicit costs include brokerage fees, commissions, and taxes that are levied upfront. Implicit costs are liquidity costs captured by bid-ask spread, market impact and vary dynamically. 
Though the explicit costs are common across all stocks, the implicit costs can differ depending upon the stock (il)liquidity. Higher are these costs, higher is the deviation which will not get corrected by arbitrageur.

Short selling constraints are regulatory constraints which prohibit the arbitrageur from naked shorting of the stock on the spot market. These constraints require the arbitrageur to borrow the stock from the market which imposes search costs on him. If the stock is limited in supply, or lending is limited, the cost of borrowing it increases (DAvolio, 2002; Ofek et al., 2004). Besides, there is also a risk of early re-call of the stock by the lender.

While the transactions costs have a symmetric impact on the positive as well as negative deviations, short selling constraints have impact only on the negative deviations, by making reverse-cash-and-carry arbitrage difficult.

In addition to the transactions costs and short selling constraints, there are funding constraints. Unlike in the perfect world, taking arbitrage positions requires capital. If access to capital becomes difficult in the form of higher fund raising costs, arbitrageurs maynot be able to enter the market and correct the mispricing (Shleifer and Vishny, 1997; Gromb and Vayanos, 2002). Thus, higher funding constraints increase the size of deviation which may persist for longer periods of time.

The market frictions described above collectively make arbitrage risky ${ }^{13}$ and costly. Opportunities for arbitrage arise only when $z_{t}$ is large enough to compensate for costs arising out of these frictions. That is, when

$$
\left|z_{t}\right| \geq C_{t}
$$

where $C_{t}$ represents the costs beyond which expected returns from an arbitrage position is higher than the expected costs at time $t$. Thus, $C_{t}$ constitutes an imaginary no-arbitrage bands that get created around the theoretical futures price within which arbitrage is not profitable. Depending on the level of transactions cost, the threshold level, $C_{t}$ can vary overtime. $C_{t}$ can be asymmetric due to market frictions such as short selling constraints. Our first focus is to determine the no-arbitrage bands for the sample of stocks analysed in this study.

While some of the market frictions noted above can be observed directly (e.g explicit costs such as taxes), others such as the implicit costs, effect of short selling constraints cannot be observed directly. This motivates the need for an econometric approach to estimate the upper and the lower thresholds within which arbitrage is not profitable. We follow Yadav et al. (1994) and use a three-regime threshold autoregressive (TAR) model to estimate these bands. Several subsequent studies including Dwyer et al. (1996), Martens et al. (1998), Kim et al. (2010) use the same approach. Even though these models allow for multiple regime TAR models, we constrain this exercise to a three-regime model. Multiple regimes in no-arbitrage bands can be expected because different arbitrageurs may face different costs,

\footnotetext{
${ }^{13}$ High variation in stock liquidity and high stock volatility increase the riskiness of the arbitrage position
} 
especially in the case of constrained arbitrage capital. Forbes et al. (1999) however argue that arbitrage is undertaken by large sophisticated financial institutions, and it is less likely that these institutions will leave opportunities for less equipped arbitrageurs. Besides, the upper and the lower thresholds immediately outside the no-arbitrage bands indicate the minimum level of costs faced by the arbitrageurs.

The three regime TAR model on the basis for a particular stock is given as:

$$
\begin{array}{rlc}
z_{t}=\phi_{0}^{(1)}+\sum_{k=1}^{p} \phi_{i}^{(1)} z_{t-k}+\epsilon_{t}^{(1)} & z_{t-d} \leq C_{1, t} \\
z_{t}=\phi_{0}^{(2)}+\sum_{k=1}^{p} \phi_{i}^{(2)} z_{t-k}+\epsilon_{t}^{(2)} & C_{1, t} \leq z_{t-d} \leq C_{2, t} \\
z_{t}=\phi_{0}^{(3)}+\sum_{k=1}^{p} \phi_{1}^{(3)} z_{t-k}+\epsilon_{t}^{(3)} & z_{t-d}>C_{2, t}
\end{array}
$$

where, $k$ indicates the lag structure to be imposed on $z_{t}, C_{1, t}$ is the lower threshold when $z_{t}$ is negative at time $t$, while $C_{2, t}$ is the upper threshold when $z_{t}$ is positive. Arbitrage opportunities emerge only when $z_{t}$ exceeds either $C_{1, t}$ or $C_{2, t}$. 'd' is the delay parameter. It determines the lag with which arbitrageurs enter the market. $\epsilon_{t}^{j}$ is i.i.d $\left(0, \sigma^{(j) 2}\right), j$ indicates the upper $\left(z_{t-d} \leq C_{1, t}\right)$, middle $\left(C_{1, t} \leq z_{t-d} \leq C_{2, t}\right)$ or the lower regime $\left(z_{t-d}>C_{2, t}\right)$.

If arbitrageurs enter the market, the next observations of $z_{t}$ will move rapidly towards zero. However, when the absolute value of $z_{t}$ is small, arbitrage will not be profitable and $z_{t}$ may not change much (Martens et al. (1998)). Thus, in the upper and the lower regime, $z_{t}$ is expected to follow a stationary process, while in the middle regime, it may follow a non-stationary process ${ }^{14}$

We estimate the model on each stock each day using 1-second frequency data. We use Akaike Information Criterion (AIC) to determine the lag length. We also need to select the set of delay parameters, $S$, to be used in the model estimation. Since different stocks have different liquidity costs, the delay parameter is expected to differ across stocks. We use a variety of values for delay parameters, $S=1,5,15,20,30,45,60,75,100,120,140,160,180,240,300$ and then pick the model which meets the stationarity condition as well as has the minimum AIC value ${ }^{15}$ Since a minimum percentage of observations are expected to be in the no-arbitrage regime, we constrain a minimum percentage of such observations to $40 \% .16$ The difference between the estimated upper and the lower threshold constitutes the size of the no-arbitrage band, or the bandwidth (bw).

Table 4 presents the estimates of the upper and lower thresholds obtained from the estimation of the TAR model for the full sample as well as sub-samples based on liquidity costs quartiles.

\footnotetext{
${ }^{14}$ For $z_{t}$ to be stationary, the sum of the coefficients $\left(\phi_{i}^{j}\right)$ in the upper and the lower regime should strictly be less than 1 .

${ }^{15}$ In some cases, we find that the basis is negative (positive) for the entire day. In that case, the model estimates both the thresholds as negative (positive) values. In such cases, we constrain the upper (lower) threshold as zero, and use the regime from zero to the upper (lower) threshold obtained from model estimation as the no-arbitrage zone.

${ }^{16}$ We repeat the exercise by changing this to $30 \%, 50 \%$, but it does not have any impact on the results
} 
Table 4 Estimated no-arbitrage bands from TAR model

The table presents the estimated values of the upper and the lower thresholds obtained from the estimation of a three-regime TAR model for all stocks in the sample. Quartiles are based on liquidity costs as defined in Section 3.2. For each stock, we first estimate the threshold values for each day, and then take an average across all days.

\begin{tabular}{l|rrrr|rrrr}
\hline Liquidity & \multicolumn{4}{|c|}{ Lower threshold } & \multicolumn{4}{c}{ Upper threshold } \\
quartiles & Mean & SD & Median & MAD & Mean & SD & Median & MAD \\
\hline All & -0.15 & 0.16 & -0.12 & 0.04 & 0.03 & 0.04 & 0.02 & 0.04 \\
& & & & & & & & \\
Q1 (Most) & -0.13 & 0.09 & -0.11 & 0.04 & 0.01 & 0.01 & 0.00 & 0.00 \\
Q2 & -0.14 & 0.09 & -0.12 & 0.06 & 0.02 & 0.02 & 0.01 & 0.01 \\
Q3 & -0.18 & 0.27 & -0.12 & 0.03 & 0.04 & 0.03 & 0.04 & 0.03 \\
Q4 (Least) & -0.15 & 0.11 & -0.13 & 0.04 & 0.07 & 0.06 & 0.04 & 0.05
\end{tabular}

The reported values are the mean and median values of the lower and upper threshold across stocks (obtained after an averaging on all the dates for each stock). The table shows that on an average, the lower threshold is 15 bps away from the midquote price when the basis is negative, and upper threshold is 3 bps higher than the midquote price. The size of the no arbitrage band (or the bandwidth), thus, on an average is 18 bps. The asymmetricity in the estimated upper and lower threshold reflects the effect of the short selling constraints in the market. These constraints increase the costs for the arbitrageur resulting in the deviation persisting for longer periods of time when spot is overpriced and futures is underpriced.

Across liquidity quartiles, the table indicates a significant cross-sectional variation in the upper as well as the lower threshold. The size of the bandwidth increases as we move from the most liquid to the least liquid stocks, consistent with the hypothesis that higher liquidity costs raise the transactions costs of arbitrageurs. For the most liquid stocks, the upper threshold is zero, indicating not much obstruction due to liquidity and explicit costs. The lower threshold is negative and significantly different from zero, once again indicating the impact of short selling constraints. For the least liquid quartile, we see that both the upper and the lower thresholds are large, but continue to be asymmetric in nature. The average value of the lower threshold is 15 bps away from the midquote price (when the basis is negative), while the upper threshold is 7 bps when basis is positive.

We compare the size of the no-arbitrage bands with the proxy for liquidity costs: the sum of the roundtrip bid ask spread on the spot and the SSF market shown in Table 3 . We observe that only for Q1 and Q2, the estimated bands completely capture the liquidity costs, not so much for Q3 and Q4. We, however, do not put much emphasis on this mismatch since each of these measures are averages of averages of the intraday spread, and these costs fluctuate significantly during the day. 


\section{Commonality in no-arbitrage bands}

In the previous section, we estimated the no-arbitrage bands constituted by the costs $\left(C_{t}\right)$ due to market frictions. Market frictions are however likely to impact different stocks differently (Nagel, 2005). For example, stocks with higher liquidity are expected to have lower width of no-arbitrage bands, in comparison to stocks with lower liquidity. Similarly, higher levels of liquidity risk on a stock make arbitrage risky, and reduce the incentive for arbitrageurs to enter the market. These stock-specific factors cause significant cross-sectional variation in the size of no-arbitrage bands.

However, to the extent that these factors affect all stocks similarly, some commonality in no-arbitrage bands is expected. Just as common factors such as market volatility, market return and market liquidity affect the systematic liquidity and systematic risk of firm's returns (Kamara et al. , 2008), ${ }^{17}$ these factors also result in a commonality in the no-arbitrage bands. This commonality is the systematic component in the size of bands which is nondiversifiable. Thus, we conjecture that the size of the no-arbitrage bands is determined by $C$, which in turn can be decomposed as

$$
C_{t}=C_{s, t}+C_{i, t}
$$

where $C_{s, t}$ represents the systematic component, while $C_{i, t}$ represents the idiosyncratic component. The subscript $t$ indicates that both the systematic and the idiosyncratic factor can differ overtime. Changes in market liquidity, market volatility, funding constraints, and taxes can cause $C_{s, t}$ to vary. Similarly, changes in the stock specific liquidity, and volatility $C_{i, t}$ can cause $C_{i, t}$ to vary overtime.

In this section, we examine if such commonality (or the systematic component) exists in no-arbitrage bands on the SSF and the spot market. We investigate the commonality by using principal component analysis (PCA) as proposed by Hasbrouck and Seppi (2001).18 The technique uses linear combinations of the original variables (example, cross-sectional data of no-arbitrage bands in our case) to explain the variance-covariance structure of the underlying data. The linear combinations are chosen to maximise the explanatory power, with the first linear combination having the maximum explanatory power.

Let $x_{i, t}$ be a variable observed for security $i$ at time $t$. In our case, $x_{i, t}$ represents the noarbitrage band. For $N$ securities and $T$ periods, let $X_{1}, X_{2}, \ldots, X_{N}$ be vectors of length $T$ such that $X_{i}^{T}=\left[x_{i, 1}, x_{i, 2}, \ldots, x_{i, N}\right]$, let $X$ be the matrix $\left[X_{1}, X_{2}, \ldots, X_{N}\right]$, and let $\Sigma$ be the covariance matix of $X$. A combination such as:

$$
Y_{j}=\gamma_{j}^{T} X=\gamma_{1, j} X_{1}+\gamma_{2, j} X_{2}+\cdots+\gamma_{N, j} X_{N}
$$

\footnotetext{
${ }^{17}$ Kamara et al. $(2008)$ argue that the common factors capture the market conditions that affect the supply of liquidity of market makers and produce correlated trading by investors.

${ }^{18}$ Subsequent studies including Corwin and Lipson (2011), Lee et al. (2012) also followed this technique to extract common components from microstructural variables such as order flow, trading volumes.
} 
represents one of the linear combinations that could represent one common factor $Y_{j}$. The variance of $Y_{j}$ is defined as $\gamma_{j}^{T} \Sigma \gamma_{j}$.

If $\gamma_{j}$ maximises the variance of $Y_{j}$, then $Y_{j}$ is referred as the first principal component. The second component is the linear combination that maximises the variance of $Y_{j}$ subject to the condition that it is uncorrelated with the first principal component. There can be as many as $N$ principal components extracted in this manner, conditional on each being uncorrelated with all previously extracted principal components (Corwin and Lipson, 2011).

In terms of eigenvalues and eigenvectors, the variance of the first principal component, $\lambda_{1}=\operatorname{Var}\left(Y_{1}\right)$, equals the first eigenvalue of $\Sigma$ and the coefficient vector, $\gamma_{1}$, equals the first eigenvector. Similar notation can be used for each of the $N$ principal components. Eigenvalues are used to determine the strength of the commonality, and individual security loadings of the eigenvector are used as a means of interpreting the common component.

Hasbrouck and Seppi (2001) suggest standardizing all the variables of the underlying data to unit variances while performing principal component analysis. In our analysis, this is not a concern since, the elements of $X_{i, t}$ only represent the no-arbitrage bands for different stocks, and are therefore consistent in units. We still standardize all the values for each stock to zero mean and unit variance 19

After standardization, total variation in $X$ equals the number of original variables (the number of stocks in our context). Thus, the proportion of total variation explained by the $j^{\text {th }}$ principal component equals:

$$
\frac{\lambda_{j}}{\lambda_{1}+\lambda_{2}+\cdots+\lambda_{N}}=\frac{\lambda_{j}}{N}
$$

Conditional on the first component explaining a significant variation in the underlying data, we propose to use the first component as the systematic component of the no-arbitrage bands.

We perform PCA on the no-arbitrage bands estimated for all the 141 stocks. We find that the first three components explain about $37 \%$ of total variation in the no-arbitrage bands across stocks, with the first component explaining $17 \%$ variation. The second and third components explain $11 \%$ and $8 \%$ variation respectively. This provides evidence of commonality in the size of the no-arbitrage bands.

\section{Economic interpretation of the first component of bandwidth}

We examine the loadings allocated to different stocks in the first principal component to draw inferences on economic interpretation of this factor. Figure 1 plots the loadings of the first component. The two plots show the loadings on stocks sorted by liquidity costs (in ascending order) and market capitalisation (in descending order). While we see that for most of the stocks the loadings are positive, there does not emerge any clear pattern in weights allocation in terms of market capitalisation or liquidity costs.

\footnotetext{
${ }^{19} \mathrm{We}$ do not find any difference in the results without standardization.
} 
Figure 1 Eigenvector of the first component from PCA on bandwidth

The figure plots the eigenvector loading on stocks from the first principal component for no-arbitrage bands. The first plot shows the loadings on stocks sorted by increasing liquidity costs, while the second plot shows the loadings on stocks sorted by decreasing market capitalisation.
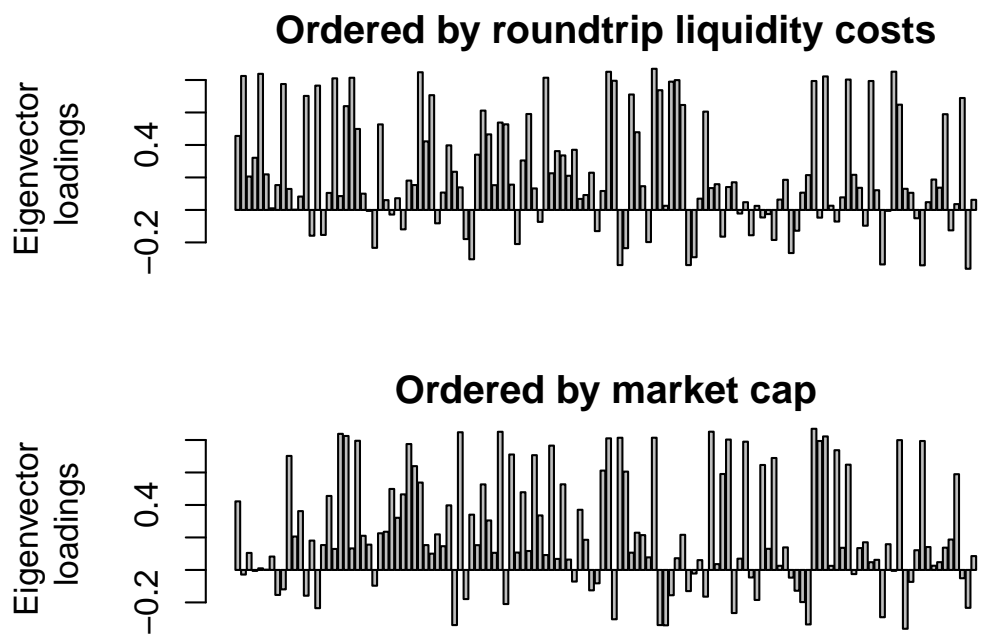

We use the first component as the component reflecting the systematic factor in the noarbitrage bands. We derive it by multiplying the matrix of stock-wise bandwidth with the vector of the loadings attached to each stock. Figure 2 plots the time-series of the first component. The higher values of the measure indicates a worsening of the arbitrage efficiency in the market, reflected by wider size of the bands. We observe a significant surge in the size of bands in mid-July when the Reserve Bank of India intervened in the money markets by raising interest rates to contain the exchange rate volatility. ${ }^{20}$

\section{Determinants of variation in the systematic compo- nent}

Given the evidence of commonality in no-arbitrage bands, we now turn to examining its sources. We describe the factors that may affect the systematic component below:

1. Funding liquidity: Brunnermeier and Pedersen (2009) argue that the ease with which an asset is traded depends on the ease with which traders can obtain funding. Higher fund raising costs affect traders adversely by increasing the inventory carrying costs for market makers, and cost of capital for arbitrageurs (Shleifer and Vishny, 1997; Gagnon and Karolyi, 2010; Rosch

${ }^{20}$ See Section 3.1 for more details on the intervention. 
et al., 2014). Tightness in funding liquidity not only affects the market liquidity (Rosch and Kaserer, 2013; $\mathrm{Hu}$ et al., 2013), but also the arbitrage activity in the market. Thus, fluctuations in the cost of accessing capital is likely to have an impact on the systematic component of the size of the no-arbitrage bands. As described earlier, we use MIBOR to capture tightness in funding liquidity.

2. Market variables: The systematic component of no-arbitrage bands is also expected to be affected by aggregate market variables such as market liquidity $\left(\operatorname{Liq}_{m}\right)$, market liquidity risk $\left(\right.$ LiqRisk $\left._{m}\right)$, and market volatility $\left(V_{o l}\right)$. Higher market volatility increases the risk of maintaining inventory which puts an upward pressure on spreads that market makers charge (Chordia et al., 2000 ). The commonality in these market variables constitute the non-diversifiable risk making arbitrage risky. We use the aggregate market values of each of these variables as possible sources of variation in the systematic component.

To derive the aggregate market component of each of these market variables, we follow two approaches: One, we use equally weighted average of each of these variables across all stocks (as followed in Chordia et al. (2000) as measure of market liquidity). As a second approach, we conduct a PCA on the standardized values of each of these measures and use their first component as the market component.

3. Explicit costs such as change in taxes: To the extent that the values of explicit costs (see Table 1) are constant during the period, the explicit costs get accounted by the mean of the systematic component. However, the period under study also saw a reduction in the STT on the derivatives market. We account for that by including a dummy in our regression framework.

We use these variables in a regression setup to determine the extent to which they affect the systematic component.

\subsection{Univariate analysis}

We estimate the following regression using each factor conjectured as a possible source of variation in the bands:

$$
P_{t}^{B W}=\alpha+\beta_{0} \times \text { Factor }_{t}+\beta_{1} \times \text { Dummy }_{t}+\epsilon_{t}
$$

where $P_{t}^{B W}$ denotes the first principal component (or the systematic factor) on the size of the no-arbitrage bands (or the bandwidth) on day $t$; Factor $t \in\left(\right.$ MIBOR, Liq $m$, Vol $_{m}$, LiqRisk $_{m}$ ); Dummy $_{t}$ accounts for STT reduction during the period of analysis. It takes value 1 for days after May 31, 2013, 0 otherwise.

Table 5 presents regression estimates of Equation 1 with each factor in one model. Panel A shows regression results with equally weighted average market variables such as liquid- 
ity, liquidity risk and volatility as market outcomes ${ }^{21}$ We find a positive and significant association of liquidity, liquidity risk and stock volatility with the systematic component. A one standard deviation increase in market (il)liquidity brings about 23.5 standard deviation increase in the size of the bands. Similarly, higher levels of liquidity risk and price risk have an adverse impact on market efficiency by widening the size of the systematic component of the bands. The dummy variable turns out to be negative and significant, indicating that a decline in STT in June 2013 improved market efficiency by bringing down the size of the bands. However, it should be noted that a regression with only the dummy variable by itself had a negligible explanatory power.

Panel B of the table reports the regression results with market values computed using the first principal component of each of the market variables.22 The findings based on the first component are similar to the findings from the equally weighted average of each market variable measure. The $R^{2}$ using each of these market variable related measures range between $4-10 \%$.

The last panel of Table 5 indicates the regression results with MIBOR as the explanatory variable. We find a positive and significant relation between MIBOR and the systematic component of no-arbitrage bands. A 1 standard deviation increase in MIBOR results in 1.22 standard deviation increase in the size of the systematic component of the bands. The $R^{2}$ also turns out to be $18 \%$ indicating MIBOR has a significant explanatory power in determining the size of the bands.

\subsection{Multivariate analysis}

Each of the factor used in the regression in Table 5 is likely to be correlated to the other factor. For example, funding costs determine the capital available to traders to trade in the market, which affects the market variables: liquidity, liquidity risk as well as volatility. In addition, each of these three variables exhibit significant correlation between each other ${ }^{23}$ Thus, a regression with all these variables in one equation will result in issues related to multicollinearity.

We eliminate the correlation between these variables by performing a principal component analysis on the average market values of each of these variables ${ }^{24}$ We use the first principal component from the PCA on these market variables and re-estimate the regression specified in Equation 1 .

The first principal component $\left(P_{M F}\right)$ extracted from a PCA on Liq $_{m}$, LiqRisk $_{m}$ and Vol $_{m}$

\footnotetext{
${ }^{21}$ We derive the market-based value of these measures by taking an equally weighted average of each of these measures across all stocks.

${ }^{22}$ Appendix A describes the principal component analysis results on each variable in detail.

${ }^{23}$ These three variables amongst themselves have a correlation coefficient greater than 0.75.

${ }^{24}$ We use our first approach, that is, equally weighted average across stocks in the principal component analysis.
} 
Table 5 Regression results on systematic component of bandwidth

The table reports regression estimates for the equation:

$$
P_{t}^{B W}=\alpha+\beta_{0} \times \text { Factor }_{t}+\beta_{1} \times \text { Dummy }_{t}+\epsilon_{t}
$$

where $P_{t}^{B W}$ denotes the first principal component (or the systematic factor) on the size of the no-arbitrage bands (or the bandwidth) on day 't'; Factor ${ }_{t} \in$ (MIBOR, Liq $_{m}, \mathrm{Vol}_{m}$, LiqRisk $_{m}$ ); Dummy accounts for STT reduction during the period of analysis. It takes value 1 for days after May 31, 2013, 0 otherwise. Panel A indicates the results based on equally weighted average of each market variable across all stocks. Panel $\mathrm{B}$ indicates the regression results based on the first principal component of each market variable. Panel C reports the regression results with funding constraints as the explanatory variable in the regression. The regression estimates are robust to the outliers in the data. The values in parenthesis indicate the t-statistic of the estimated coefficient.

\begin{tabular}{lcccc}
\hline Factor & $\beta_{0}$ & $\beta_{1}$ & $R^{2}$ & \# of obs. \\
\hline Panel A & & & & \\
\hline Liq $_{m}$ & 22.28 & -0.91 & 0.04 & 113 \\
& $(2.27)$ & $(-1.87)$ & & \\
LiqRisk $_{m}$ & 97.34 & -0.63 & 0.04 & 113 \\
& $(1.89)$ & $(-1.27)$ & & \\
Vol $_{m}$ & 0.10 & -1.29 & 0.09 & 113 \\
& $(3.33)$ & $(-2.96)$ & &
\end{tabular}

\begin{tabular}{lcccc} 
Panel B & & & & \\
\hline Liq $_{p c 1, m}$ & 0.13 & -1.25 & 0.09 & 113 \\
& $(3.66)$ & $(-3.21)$ & & \\
LiqRisk $_{p c 1, m}$ & 0.08 & -0.81 & 0.06 & 113 \\
& $(2.43)$ & $(-1.89)$ & & \\
Vol & & & \\
& 0.13 & -1.30 & 0.10 & 113 \\
& $(3.47)$ & $(-2.96)$ & & \\
Panel C & & & & \\
\hline MIBOR & 1.06 & -0.90 & 0.18 & 113 \\
& $(6.56)$ & $(-2.74)$ & &
\end{tabular}

explains $76 \%$ variation in these factors collectively, indicating a significant correlation across the three variables. Further, since all these market variables are also affected by changes in funding liquidity, we cannot include MIBOR in the same regression. The correlation coefficient between MIBOR and $P_{M F}$ turns out to be 0.77 . To eliminate multicollinearity, we repeat the principal component analysis exercise by adding MIBOR as the fourth factor along with the market values of the three market variables $\left(L_{i q_{m}}, L_{i q R i s k_{m}}\right.$ and $\left.V_{o l_{m}}\right)$. The first component from these four variables $\left(P_{M F, M I B O R}\right)$ explains $76 \%$ of the variation.

Figure 2 plots the time-series of the systematic component of no-arbitrage bands along with the first component based on the three market variables $\left(P_{M F}\right)$ and with the first component based on all the four variables including MIBOR $\left(P_{M F, M I B O R}\right)$. We also add MIBOR to the plot to indicate changes in the costs of funding during the period under study. The dashed 
Figure 2 Time series of the systematic factor with other factors

The figure plots the systematic factor along with the first component extracted from a principal component analysis on only the three market variables: market liquidity, market liquidity risk and market volatility; and from the three market variables and MIBOR. The figure also plots MIBOR. The dashed line indicates the date of intervention by the Reserve Bank of India to contain exchange rate volatility.

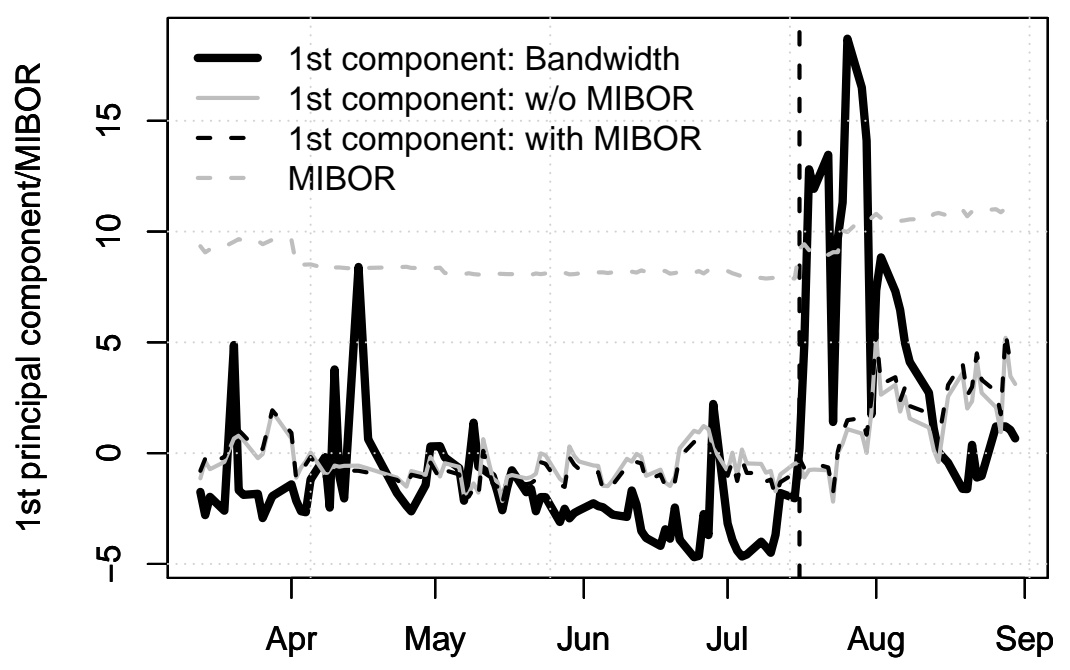

line in the graph indicates the date of intervention by the central bank of India, when the interest rates in the money market were increased to contain exchange rate volatility. The graph shows an increase in the systematic component with the date of increase in the interest rates, indicating how sudden tightness in the funding liquidity affected the arbitrage trades. The increase in the systematic component of the market variables continues until a few days after the increase in MIBOR.

The above observations are reflected in our regression results as well. Table 6 reports the estimates results using $P_{M F}$ as a factor, along with the STT dummy (See M1). As we observed in the univariate results, there is a positive and significant association between the systematic component of the size of no-arbitrage bands and market variables. A deterioration in the market variables causes an increase in the systematic component of the size of the bands. Model 2 (M2) in Table 6 shows the regression results by using $\left(P_{M F, M I B O R}\right)$ as the explanatory variable along with the STT dummy. We find similar results as in M1, with the explanatory power of the model improving from $7 \%$ to $10 \%$. The results suggest that funding constraints have a key role in determining arbitrage efficiency in the markets. The results are similar to the findings by Rosch et al. (2014) who also find that funding liquidity plays a significant role in determining aggregate market efficiency. 
Table 6 Multivariate regression results

The table presents results of the regression estimated for the equation:

$$
P_{t}^{B W}=\alpha_{0}+\beta_{0} \times P_{M F, t}+\beta_{1} \times \text { Dummyt }+\epsilon_{t}
$$

where $P_{t}^{B W}$ denotes the first principal component (or the systematic factor) on the size of the noarbitrage bands (or the bandwidth) on day ' $t$ '; $P_{M F, t}$ is the first component on the market variables

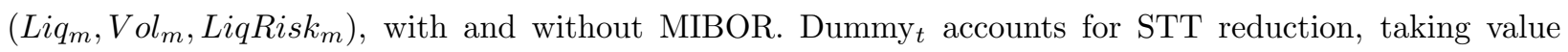
1 for days after May 31, 2013, 0 otherwise. The regression estimates are robust to the outliers in the data. The values in parenthesis indicate the t-statistic of the estimated coefficient.

\begin{tabular}{|c|c|c|}
\hline & M1 & M2 \\
\hline Dummy & $\begin{array}{l}-1.03 \\
(-2.94)\end{array}$ & $\begin{array}{c}-1.08 \\
(-2.69)\end{array}$ \\
\hline$P_{M F}$ & $\begin{array}{c}0.54 \\
(2.94)\end{array}$ & \\
\hline$P_{M F, M I B O R}$ & & $\begin{array}{c}0.55 \\
(3.64)\end{array}$ \\
\hline $\mathrm{R}^{2}$ & 0.07 & 0.10 \\
\hline \# of obs. & 113 & 113 \\
\hline
\end{tabular}

\section{Conclusion}

Several papers in the past have explored the effect of limits to arbitrage in the context of index futures and spot, but none on the stock futures and spot data. This study attempts to fill this gap by investigating the effect of market frictions on arbitrage in(efficiency) in a much more cleaner setting of stock futures and spot prices. Market frictions result in no-arbitrage bands around the theoretical prices of futures. We find that on an average, when there is negative deviation, the mispricing persists atleast until it is less than equal to 15 bps away from the midquote price. On the positive side, this limit is smaller, to the extent of $3 \mathrm{bps}$. Consistent with the prior literature, this asymmetricity in the upper and the lower limit, reflects the effect of the short selling constraints on the spot market (Ofek et al., 2004). Evidence of significant cross-sectional variation in the size of the bands is also found, which can be explained by the differences in the liquidity of the stock.

We also explore the possibility of commonality in the size of no-arbitrage bands. We conjecture that a part of these bands can be explained by market-related factors common to all stocks (the systematic factor) and the rest to the stock-specific factor (the idiosyncratic factor). We find evidence of such commonality. $17 \%$ of the variation in the size of no-arbitrage bands can be explained by the first principal component, which we refer as the systematic component. This finding links with the commonality literature which has so far focused on the returns (Fama and French, 1995), liquidity (Chordia et al., 2000), and very recently, market efficiency (Rosch et al., 2014).

We delve into the factors that can be attributed to the variation in the systematic component. 
We find that explicit factors like taxes, market factors like liquidity and volatility have a significant explanatory power in explaining the variation. The factor that has maximum explanatory power turns out to be funding constraints captured by MIBOR. This evidence is consistent with the recent literature which asserts that funding liquidity is a key factor in determining market liquidity. We find that tightening of the interest rates in the money market by the central bank worsened the arbitrage efficiency of the equity markets, an unintended consequence of an action by the regulator. 


\section{A Principal component analysis results on market vari- ables}

Table 7 presents the results of principal component analysis on each of the market variable: Liquidity, liquidity risk and stock volatility. The eigenvalues of the first component on these variables range between $44-50 \%$, indicating a significant level of commonality. The first component on liquidity variable explains about $45 \%$ of the total variation in liquidity across all stocks. Similarly on liquidity risk and stock volatility, the first component explains about $49 \%$ and $44 \%$ of total variation. The second and the third component share for each of these variables is less than $10 \%$.

Table 7 Eigenvalues obtained from PCA on market outcomes

\begin{tabular}{lccccccc}
\hline & Mean & Median & SD & \multicolumn{3}{c}{ Eigenvalues } & Cumulative \\
\cline { 5 - 7 } & & & & 1 & 2 & 3 & $\begin{array}{l}\text { explained } \\
\text { variance (\%) }\end{array}$ \\
\hline Liquidity & 0.21 & 0.18 & 0.13 & 45.09 & 7.40 & 3.68 & 56.17 \\
LiqRisk & 0.03 & 0.02 & 0.02 & 49.52 & 7.41 & 5.97 & 62.90 \\
Volatility & 39.42 & 34.66 & 19.97 & 44.75 & 4.68 & 3.86 & 53.29 \\
\hline
\end{tabular}

Figure 3 also plots the weights assigned to each stock in the first component computation. We see that for all the three variables, the weights are generally positive and similar, indicating that this component captures the systematic component of each of these variables.

Figure 3 Loadings on the first component from PCA on market outcomes
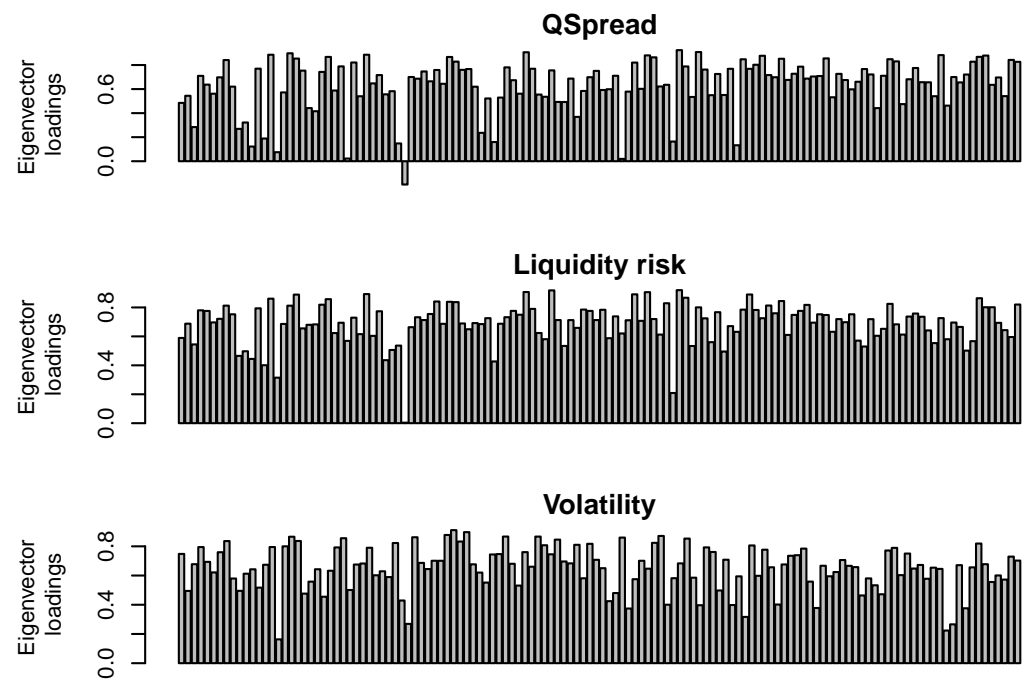


\section{References}

Ackert LF, Tian YS (2001). "Efficiency in index options markets and trading in stock baskets." Journal of Banking and Finance, 25(9), 1607 - 1634.

Brenner M, Subrahmanyam MG, Uno J (1990). "Arbitrage Opportunities in the Japanese Stock and Futures Markets." Financial Analysts Journal, 46(2), 14 - 24.

Brooks C, Garrett I (2002). "Can we explain the dynamics of the UK FTSE 100 stock and stock index futures markets?" Applied Financial Economics, 12(1), 25-31.

Brunnermeier M, Pedersen LH (2009). "Market liquidity and funding liquidity." Review of Financial Studies, 22(6), 2201-2238.

Chordia T, Roll R, Subrahmanyam A (2000). "Commonality in liquidity." Journal of Financial Economics, 56(1), 3 - 28. URL http://www.sciencedirect.com/science/ article/pii/S0304405X99000574.

Chung YP (1991). "A Transactions Data Test of Stock Index Futures Market Efficiency and Index Arbitrage Profitability." The Journal of Finance, 46(5), 1791-1809.

Cornell B, French K (1983). "Taxes and the Pricing of Stock Index Futures." Journal of Finance, 38, 675-694.

Corwin SA, Lipson ML (2011). "Order characteristics and the sources of commonality in prices and liquidity." Journal of Financial Markets, 14(1), 47 - 81. URL http: //wWw.sciencedirect.com/science/article/pii/S138641811000025X.

Cremers M, Weinbaum D (2010). "Deviations from Put-Call Parity and Stock Return Predictability." null, 45, 335-367.

Dwyer G, Locke P, Yu W (1996). "Index Arbitrage and Nonlinear Dynamics Between the S\&P 500 Futures and Cash." Review of Financial Studies, 9(1), 301-332.

DAvolio G (2002). "The market for borrowing stock." Journal of Financial Economics, 66(23), 271 - 306. ISSN 0304-405X. Limits on Arbitrage.

Fama EF, French KR (1995). "Size and Book-to-Market Factors in Earnings and Returns." The Journal of Finance, 50(1), 131-155.

Figlewski S (1984). "Performance and basis risk in stock index futures." Journal of Finance, 40, 657-670.

Forbes CS, Kalb GRJ, Kofman P (1999). "Bayesian Arbitrage Threshold Analysis." Journal of Business and Economic Statistics, 17(3), 364-372.

Fung JKW, Draper P (1999). "Mispricing of index futures contracts and short sales constraints." Journal of Futures Markets, 19(6), 695-715. 
Gagnon L, Karolyi GA (2010). "Multi-market trading and arbitrage." Journal of Financial Economics, 97(1), 53 - 80. URL http://www.sciencedirect.com/science/article/ pii/S0304405X10000486.

Gay GD, Jung DY (1999). "A further look at transaction costs, short sale restrictions, and futures market efficiency: The case of Korean stock index futures." Journal of Futures Markets, 19(2), 153-174.

Gromb D, Vayanos D (2002). "Equilibrium and welfare in markets with financially constrained arbitrageurs." Journal of Financial Economics, 66(23), 361 - 407.

Grover R (2014). "Securities lending: A key missing link in the Indian securities markets." Ajay Shah blog. URL http://ajayshahblog.blogspot.in/2014/07/ securities-lending-key-missing-link-in.html.

Hasbrouck J, Seppi DJ (2001). "Common factors in prices, order flows, and liquidity." Journal of Financial Economics, 59(3), 383 - 411. URL http://www.sciencedirect. com/science/article/pii/S0304405X0000091X

Hu GX, Pan J, Wang J (2013). "Noise as Information for Illiquidity." The Journal of Finance, 68(6), 2341-2382. ISSN 1540-6261. URL http://dx.doi.org/10.1111/jofi.12083.

Huberman G, Halka D (2001). "Systematic Liquidity." Journal of Financial Research, 24(2), $161-78$.

Kamara A, Lou X, Sadka R (2008). "The divergence of liquidity commonality in the crosssection of stocks." Journal of Financial Economics, 89(3), 444- 466.

Karolyi GA, Lee KH, van Dijk MA (2012). "Understanding commonality in liquidity around the world." Journal of Financial Economics, 105(1), 82 - 112. URL http: //www.sciencedirect.com/science/article/pii/S0304405X11002844.

Kim B, Chun S, Min H (2010). "Nonlinear dynamics in arbitrage of the S\&P 500 index and futures: A threshold error-correction model." Economic Modelling, 27, 566-573.

Klemkosky R, Lee J (1991). "The intraday ex post and ex ante profitability of index arbitrage." Journal of Futures Markets, 11(3), 291-311.

Lamont OA, Thaler RH (2003). "Anomalies: The Law of One Price in Financial Markets." Journal of Economic Perspectives, 17(4), 191-202.

Lee HC, Chien CY, Liao TH (2012). "Commonality in trading activity and futures-cash basis: Evidence from the Taiwan futures and stock markets." Journal of Futures Markets, 32(10), 964-994. ISSN 1096-9934.

Mackinlay C, Ramaswamy K (1988). "Index futures arbitrage and the behavipur of stock index futures prices." Review of Financial Studies, 1, 137-158. 
Martens M, Kofman P, Vorst T (1998). "A threshold error correction model for intraday futures and index returns." Journal of Applied Econometrics, 13, 245-263.

McMillan DG, Philip D (2012). "Short-sale constraints and efficiency of the spot-futures dynamics." International Review of Financial Analysis, 24, 129-136.

McMillan DG, Speight AEH (2006). "Nonlinear dynamics and competing behavioral interpretations: Evidence from intra-day FTSE-100 index and futures data." Journal of Futures Markets, 26(4), 343-368.

Miller MH, Muthuswamy J, Whaley RE (1994). "Mean Reversion of Standard \& Poor's 500 Index Basis Changes: Arbitrage-Induced or Statistical Illusion?" Journal of Finance, 49(2), 479-513.

Modest DM, Sundaresan M (1983). "The relationship between spot and futures prices in stock index futures markets: Some preliminary evidence." Journal of Futures Markets, 3(1), 15-41.

Nagel S (2005). "Short sales, institutional investors and the cross-section of stock returns." Journal of Financial Economics, 78(2), 277 - 309.

Ofek E, Richardson M, Whitelaw RF (2004). "Limited arbitrage and short sales restrictions: evidence from the options markets." Journal of Financial Economics, 74(2), 305 - 342.

Roll R, Schwartz E, Subrahmanyam A (2007). "Liquidity and the Law of One Price: The Case of the Futures-cash Basis." Journal of Finance, 62(5), 2201-2234.

Rosch C, Kaserer C (2013). "Market liquidity in the financial crisis: The role of liquidity commonality and flight-to-quality." Journal of Banking and Finance, 37, 2284-2302.

Rosch MD, Avanidhar S, van Dijk A Matchijs (2014). "An empirical analysis of comovements in high- and low- frequency metrics for financial market efficiency." Working paper, URL http://papers.ssrn.com/sol3/papers.cfm?abstract_id=2062926.

Shah A (2013). "Too sensational: The defence of the Rupee." Ajay Shah blog. URL http: //ajayshahblog.blogspot.in/2013/08/too-sensational-defence-of-rupee.html.

Shleifer A, Vishny RW (1997). "The Limits of Arbitrage." The Journal of Finance, 52(1), $35-55$.

Suvanam GK, Jalan M (2012). "Developing the securities lending and borrowing market in India." NSE Working paper, URL http://www.nseindia.com/research/content/WP_ 7_02082012.pdf.

Tse Y (2001). "Index arbitrage with heterogeneous investors: A smooth transition error correction analysis." Journal of Banking and Finance, 25(10), 1829 - 1855. 
Yadav P, Pope P (1990). "Stock index futures arbitrage: International evidence." Journal of Futures Market, 10, 573-603.

Yadav P, Pope P, Paudyal K (1994). "Threshold autoregressive models in finance: The price differences of equivalent assets." Mathematical Finance, 4, 205-221. 